\title{
Application Research Based on Flexible Management Model in Human Resource Management
}

\author{
Tong Xu
}

\author{
Shandong Normal University, Jinan, China \\ *Corresponding author Email: asd8199696@163.com
}

\begin{abstract}
Based on the characteristics and functions of flexible management, this paper analyzes the specific application of flexible management in human resource management. Flexible management helps to stimulate the creativity and enthusiasm of employees, improve the productivity of enterprises, and enhance employee cohesion. In practical applications, enterprises should pay attention to flexible job design, use flexible recruitment to introduce talents, implement flexible employee training, and establish a flexible performance evaluation mechanism.
\end{abstract}

Keywords: Flexible management; human resource management; application

\section{INTRODUCTION}

After China's economy enters a new normal period, enterprises are facing an increasingly fierce competitive environment. In order to occupy a favorable position in the market competition, the status and importance of human resource management is increasingly prominent. Enterprise managers should improve the enthusiasm and creativity of employees through effective human resource management, and attract more outstanding talents to serve the enterprise. Based on the characteristics and functions of flexible management, this paper analyzes the specific application of flexible management in human resource management [1].

\section{The Concept and Characteristics of Flexible Management}

\subsection{The concept of flexible management}

Flexible management refers to focusing on humanization in human resource management, constructing an environment of respect and equality within the enterprise, analyzing employees 'psychological needs and behavior laws, and establishing psychological identification with corporate culture, thereby transforming corporate goals into consciousness Action. The theory of flexible management can satisfy the actual needs of employees for their own value and emotion, and is a management theory with humanistic care. At present, employees of enterprises pay more and more attention to corporate culture and working environment in the process of serving the company, and their satisfaction has an important role in the development of the company. In order to attract and retain excellent employees, companies should continue to pay attention to their emotional needs, build an excellent corporate culture, and provide guarantee for the sustainable development of the company.

\subsection{Features of flexible management}

First, the flat and networked organizational structure. The organizational structure of an enterprise is a cooperative organizational system in which people carry out management activities in order to achieve specific business objectives [2]. Flexible management reduces non-essential links in enterprise management, plays a role in decentralizing the power and responsibility of the enterprise, and enables managers above the middle level in the enterprise to exert independent decision-making ability and achieve the management effect of knowing and using effectively. Moreover, a flat organizational structure will reduce vertical management and expand horizontal management, which will help promote information exchange and communication within the enterprise. Second, flexible management decisions. Flexible management can eliminate the defects of traditional rigid management and make scientific and reasonable management decisions based on full discussion and negotiation. Because of the realization of decentralization, some of the company's decisions have also absorbed and adopted the views and suggestions of employees. At the same time, the goal of flexible management decision-making follows the principle of satisfaction, rather than the optimal principle of rigid management decision-making in the past, which can increase the satisfaction of the company's stakeholders. Third, encourage scientific organization. In the economic management of an enterprise, material incentives such as salary and bonuses are the foundation, but they can only meet the basic needs of employees, while non-material incentives can achieve higher levels of employee needs, such as respect and self-actualization. In modern enterprises, the two are often integrated. In enterprise human resources management, flexible management not 
only requires employees to be given a relaxed, equal, and respectful environment, but also promotes employees to participate in the management of the enterprise and provides them with opportunities for career development [3].

\section{The Role of Flexible Management in Human Resource Management}

\subsection{Help to mobilize the creativity and enthusiasm of employees}

In the management of human resources, the application of flexible management can effectively stimulate the enthusiasm of employees and give play to their innovative capabilities, thereby enhancing the competitiveness of enterprises. In addition to giving material incentives to employees, flexible management also attaches importance to humanized management, giving employees spiritual inspiration and emotional care, bringing psychological satisfaction to employees, forming an identification with the enterprise, mobilizing their work enthusiasm, and being able to Make greater contributions to the enterprise on the job.

\subsection{It is helpful for enterprises to improve labor productivity}

For modern enterprises, talent is one of the main factors that affect the competitiveness of enterprises. The flexible management of employees affects the enterprise's own flexibility and can cope with changes in the complicated market environment. At the same time, the flexible management method also guides employees to form efficient work methods and work habits. In the past, rigid management was often vertical and multi-level, while flexible management was networked and flat. The use of networked and flat organizations can reduce unnecessary links in the production and operation of enterprises, accelerate the transmission of information within the enterprise, improve work efficiency, and achieve the effect of increasing labor productivity.

\subsection{It is conducive to enterprises to enhance employee cohesion}

Respecting and understanding employees is an important part of corporate culture. Enterprise managers must respect employees, absorb and adopt their reasonable opinions and suggestions, and cannot blame and punish employees at will, and must respect the work results of employees. When enterprise managers really care about and understand employees, they will attach great importance to the work results achieved by employees, let them feel respected, and form a sense of trust and belonging to the enterprise, which is an important function of flexible management. If employees agree with the corporate culture and integrate their own development with corporate development, they can build common values within the company and enhance their cohesion.

\section{Enterprise Application Flexible Management Strategy}

\subsection{Emphasis on flexible work design}

Job design is the first step in flexible management of human resources. The job design clarifies the job responsibilities and work contents of different employees, and provides a basic basis for the company to carry out follow-up human resources management. The purpose of job design is to make the best use of people, improve the efficiency and effectiveness of employees, in order to facilitate the realization of corporate strategic goals. The work design of flexible management can divide the employees of the enterprise into the following types: first-line peripherals, second-line peripherals and external employees. Because the work of core employees is more challenging, they pay more attention to personal development. In the process of job design, they should be given more flexible power to give play to their enthusiasm and creativity. In business operations, there should be closer communication between managers and core employees to encourage core employees to actively participate in business management. The frontline employees have a strong sense of professionalism. In the work design, detailed work specifications should be formulated according to the work content of the front-line employees to provide guidance for them to perform their duties. For the latter two types of employees, when designing their work, because their work is specific, the content should be highly targeted.

\subsection{Make full use of flexible recruitment to introduce talents}

In the course of China's economic development, highquality talents have continuously pursued self-reliance and self-development, which has virtually accelerated the flow of talents in society, resulting in tremendous changes in the structure and nature of the labor force. Therefore, enterprises should pay attention to recruitment and hiring, and achieve their strategic goals through talent recruitment. At present, how to recruit talents suitable for the development of enterprises has become a problem for many enterprises to carry out human resources management. To implement flexible management, it is necessary to expand the recruitment channels in the recruitment process, using a combination of internal selection and external recruitment. Recruitment methods should also be flexible, and can take various forms such as college special recruitment, headhunting recruitment, and Internet recruitment. 
Enterprises should adopt different recruitment methods and methods for talents at different levels. For example, for the core employees of an enterprise, it should be based on internal selection, mainly considering employees' values, loyalty, professional skills, and comprehensive qualities.

\subsection{Implement flexible employee training}

The establishment of a flexible employee training mechanism should start from the following aspects: The enterprise should provide employees with a training mechanism that meets their personal development needs, so that they can obtain opportunities for professional ability improvement, which is of great significance for the future development of the enterprise. Enterprises can upgrade the current training system, establish an enterprise university training model, create a learning organization, expand the scope of employee training and education, so that they can establish the concept of lifelong learning. When conducting training, design personalized training programs for employees' professional, experience, interest, personality, ability tendency, and work values to ensure that the training can obtain practical results.[4]

\subsection{Establish a flexible performance evaluation mechanism}

In the process of flexible management of human resources, performance assessment is not only an important part of employees' career development, but also helps to promote the realization of corporate strategic goals.[5] Enterprises should adopt reasonable performance index extraction methods in accordance with their own business strategies, clarify the key success factors of different departments, and then use key index analysis methods to decompose the company's business objectives into different departments and each worker. Quantitative assessment indicators fully stimulate the potential of employees. At the same time, abandon the rigid assessment indicators, focusing on reflecting the enthusiasm and personal wishes of employees in the assessment.

\section{Methods of Human Resources Flexible Flow Management}

\subsection{Consolidate the talent base}

To achieve flexible flow management, high-quality employees are the basis for implementation, which is a necessary condition for enterprises to achieve flexible flow management. In the future, if enterprises want to improve their overall management level, they must move towards the direction of personalized management. They are superb in the professional field, leading in the technical field, and flexible in management.
First, we must establish the concept of lifelong learning, strengthen the grasp of the overall development of the professional field, and timely control the development in this field. Secondly, it is necessary to continuously cultivate internal functions by continuously absorbing advanced management concepts and methods. Third, flexible managers must clearly understand the environment in which their organizations are located, define the correct goals, implement work practices, and promote self-discipline and autonomous management of the enterprise.

\subsection{Establish an efficient team}

In the information age, technology is changing fast, business chains are flexible, and mechanized organizational structures are difficult to adapt to business development. Compared with the traditional organizational structure, the team of the flexible flow management system is more flexible and can respond efficiently and quickly to the environment. On the one hand, organizational leaders can accept market information and react faster, and make tactical strategies in a timely manner. On the other hand, team resources can be reorganized and optimized in time according to the market environment. In addition, due to the flexible and changeable team structure, it is easier to form a flat and democratic atmosphere, which helps to gather the wisdom and resources of all parties and allow enterprises to improve their responsiveness and adaptability in a complex and changing environment. The development of the enterprise seizes the opportunity.

\subsection{Form a flexible mechanism}

The flexible mechanism is most fully reflected in working hours, which can be divided into core time flexible time according to the amount of business. During the flexible time, let the employees play independently, dominate and flexibly arrange, so that the employees have enough space and autonomy. The core time is the time for employees to work together, mainly for some meeting projects. Such a flexible mechanism can allow employees to flexibly control their working hours, coordinate the relationship between family, work, and hobbies, improve their work efficiency and stimulate their subjective initiative.

\subsection{Provide flexible incentives}

Flexible incentives mean that rigid and institutional incentives need to be reduced. It is necessary to dynamically pay attention to the needs of employees, fully respect the self-realization of employees, and the embodiment of needs in flexible mobility management. Let employees be fully motivated in a flexible environment, let their needs and the development of the company be organically assembled, and stimulate their enthusiasm. 


\subsection{Form a flexible culture}

As an enterprise manager, it is necessary to form a flexible construction of corporate culture and form flexible values. Through the concept of values, companies can continue to effectively solve organizational problems and form a consensus among employees. Today's market is changing rapidly, and the flexible management concept is deep in the heart of each employee, so that they can truly inspire the love and passion in their hearts and strive for the development of the enterprise.

\section{Conclusion}

At present, flexible management is playing an increasingly important role in human resource management. In enterprise human resource management, flexible management helps to shape an excellent corporate culture, create a relaxed working atmosphere, stimulate employees' enthusiasm and creativity, improve work efficiency, and increase labor productivity. Moreover, scientific application of flexible management can also optimize the internal management mechanism, improve the management level, and promote the sustainable development of enterprises.

\section{REFERENCES}

[1] Wang Guilin. The effective role of flexible management in enterprise economic management $[\mathrm{J}]$. Chinese Business Review, 2012 (25): 153-154.

[2] Zhang Qian. The necessity of flexible management in employee management [J]. Journal of Taiyuan Urban Vocational College, 2014 (3): 159-160.

[3] Cao Qinxian, Yu Miao. Intellectual property protection in the joint construction and sharing of information resources under the network environment [J]. Journal of Adult Education College of Hebei University, 2015 (3): 93-94.

[4] Yang Lijing. On the application of flexible management in human resources management of enterprises [J]. Management Manager, 2015 (12): 194.

[5] Song Xin, Li Rutian, Wang Qing, et al. Application of flexible management in human resources management of enterprises [J]. Commercials, 2018, 000 (007): 132. 